Polymer Journal, Vol. 3, No. 5, pp 617-623 (1972)

\title{
Electrochemical Oxidation of Polymer Anions and Arene Anions
}

\author{
Seiichi NAKAHAMA and Noboru YAMAZAKI \\ Tokyo Institute of Technology, Ohokayama, Meguro-ku, Tokyo, Japan. \\ (Received January 10, 1972)
}

\begin{abstract}
In order to investigate the reactivity of carbanions in anionic polymerizations, oscillopolarographic measurements of oxidation potentials of polymer anions and arene anions were carried out in tetrahydrofuran solutions with sodium tetraethylaluminate as a supporting electrolyte. The oxidation potentials of the carbanions measured with a microplatinum electrode were expressed against the standard potential of naphthalene radical anion: phenanthrene-, $0 \mathrm{~V}$; biphenyl-, $0 \mathrm{~V}$; anthracene-2-, $0.27 \mathrm{~V}$; stilbene2-, $0.48 \mathrm{~V}$; (polystyrene) ${ }^{2-}, 1.26 \mathrm{~V}$; [poly $\left(\alpha\right.$-methylstyrene) ${ }^{2-}, 1.13 \mathrm{~V}$; (diphenylethylene $)_{2}{ }^{2-}, 1.13 \mathrm{~V}$, poly(4-vinylpyridine) ${ }^{2-}, 1.75 \mathrm{~V}$, fluorene-, $1.71 \mathrm{~V}$. There is a linear relationship between oxidation potentials and energy level of the highest occupied molecular orbitals of these carbanions, which were obtained from the Hückel molecularorbital method. It was suggested that the oxidation wave was caused by direct electron transfer from carbanion to anode. The carbanion, which was reported to have a high reactivity for the initiation or propagation of anionic polymerization, exhibited a less noble oxidation potential. The electrolytic oxidation of disodium $\alpha$-methylstyrene tetramer yielded an oligomer of high molecular weight, 1000, in anodic compartment. For the anodic reaction, it is proposed that one electron transfer forms radical species followed by radical coupling.
\end{abstract}

KEY WORDS Electrochemical Oxidation / Arene Anion / Polymer Anion / Oxidation Potential / Oscillopolarography / Electron Transfer / Anionic Polymerization /

In previous papers on the electroinitiated anionic polymerizations, it has been confirmed by means of polarography that direct electron transfer from cathode to monomer initiates anionic polymerization and the half-wave reduction potentials of monomers are related with reactivities for anionic polymerization ${ }^{1}$. The rate of electron transfer from arene anion to monomer, which is an anionic initiation reaction, depends on the both reactivities of monomer and the arene anion. Similarly the rate of propagation of anionic polymerization is affected not only by the reactivity of monomer but also by that of the propagating end. This was elucidated experimentally by Szwarc, et al.; the rate constants of the addition of styrene monomer to polystyrene anion ${ }^{2}$, poly(4-vinylpyridine) anion $^{3}$ and diphenylethylene dimer dianion ${ }^{4}$ in tetrahydrofuran(THF) were $950, c a .1$ and $0.5-$ $0.7 \mathrm{l} / \mathrm{mol} \mathrm{sec}$ at $25^{\circ} \mathrm{C}$ respectively. These results indicate that reactivities of polymer anions are intensively influenced by their substituents. As it can be assumed that carbanions such as naphthalene ${ }^{-}$, biphenyl ${ }^{-}$, initiate anionic polymerization through an electron-transfer process and the transition state of anionic propagation reaction is similar to that of electron-transfer reaction, reactivities of carbanions could be estimated by the electrochemical measurements of oxidation potentials of the carbanions. There have been few investigations of the electrochemical oxidation of carbanions. Funt, et al., described the electrochemical production and destruction of the living anion of $\alpha$-methylstyrene in THF solution of sodium tetraethylaluminate $\left(\mathrm{NaAlEt}_{4}\right)$ or other salts ${ }^{5}$; when the polarity of the electrode was reversed, it was found that the same quantity of charge was required to decolorize the solution of $\alpha$-methylstyryl anion as was used to form the carbanion initially. It seems that the disappearance of the color of $\alpha$-methylstyryl anion is due to the electron transfer from the carbanion to a platinum anode.

In this paper, we report a study of electro- 
chemical oxidations of polymer anions and arene anions, which are the propagating ends and initiators of anionic polymerization respectively. In order to observe the oxidation waves of the carbanions, a THF solution of $\mathrm{NaAlEt}_{4}$ was used in this study as a supporting electrolyte, which was propitious for the electrolytic formation of living polymer of $\alpha$-methylstyrene ${ }^{6}$ and isoprene $^{7}$. The oxidation potentials of the carbanions were measured by means of the oscillopolarographic method and the potentials were compared with rate constants of anionic polymerization and related with energy levels of the highest occupied molecular orbitals (HOMO) of the carbanions, which were calculated from the Hückel molecular-orbital method.

\section{EXPERIMENTAL}

\section{Materials}

Sodium Naphthalene. Sodium naphthalene was prepared by the contact of metallic sodium surface on glass with naphthalene solution in THF. According to a similar method, sodium phenanthrene, disodium anthracene, sodium biphenyl, fluorenyl sodium, disodium $\alpha$-methylstyrene tetramer, and disodium diphenylethylene dimer were prepared.

Living Sodium Polystyrene, Poly(4-vinylpyridine).

The living polystyrene and poly(4-vinyl pyridine) were produced in THF by initiating the polymerization of the respective monomers with sodium naphthalene and disodium, diphenylethylene dimer respectively.

All carbanions in THF were stored in ampoules equipped with break-seals.

\section{Oscillopolarography}

The oscillopolarographic measurements of oxidation potentials of ten carbanions, all of the accompanying positive ions were sodium cations, were conducted at $25^{\circ} \mathrm{C}$ by using an apparatus as shown in Figure 1. $\mathrm{NaAlEt}_{4}$ was used as a supporting electrolyte since the salt was oxidized at a higher potential as compared with the carbanions investigated in this study. According to Ziegler ${ }^{8}$, when molten $\mathrm{NaAlEt}_{4}$ was electrolyzed with anode of inert metal, the first product at anode was the neutral radical, $\mathrm{AlEt}_{4} \cdot$, which immediately decomposed into Et.

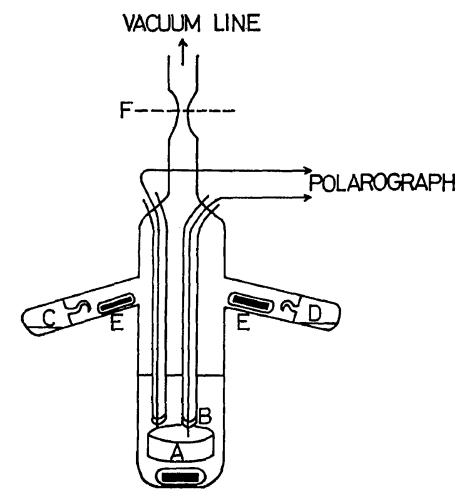

Figure 1. Polarograph cell: A, cathode made of a platinum cylinder; B, microplatinum electrode; $\mathrm{C}$ and $\mathrm{D}$, ampoules containing sodium complexes; $\mathrm{E}$, magnetic breaker; $\mathrm{F}$, sealed at $\mathrm{F}$ and isolated from vacuum line.

$+\mathrm{AlEt}_{3}$ followed by the disproportionation of the Et. to ethane and ethylene. The polarograph cell, which contained about $0.7 \mathrm{~g}$ of $\mathrm{NaAlEt}_{4}$, was dried under vacuum $\left(<10^{-5} \mathrm{mmHg}\right)$ for about $10 \mathrm{hr}$. THF, $25 \mathrm{ml}$, which was dried with $\mathrm{LiAlH}_{4}$ and degassed under vacuum, was transferred into the cell via the trap-to-trap method, subsequently the cell was sealed at $\mathbf{F}$ and isolated from the vacuum line. From ampoules $C$ and $D$, which contained for instance naphthalene anion and anthracene dianion respectively, the solution of carbanion was introduced into the cell through a breakable-seal. The cell was maintained at $25^{\circ} \mathrm{C}$ in a constant temperature bath and the solution was stirred by a magnetic bar. After stopping the agitation, the oxidation waves were observed by means of

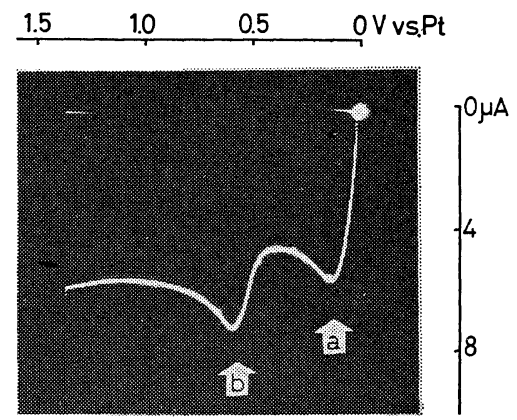

Figure 2. Oscillopolarogram of sodium naphthalene (a) and disodium anthracene (b): sweep rate, $0.2 \mathrm{~V} / \mathrm{sec}$; sweep range, $0-1.4 \mathrm{~V}$ vs. $\mathrm{Pt}$ electrode. 

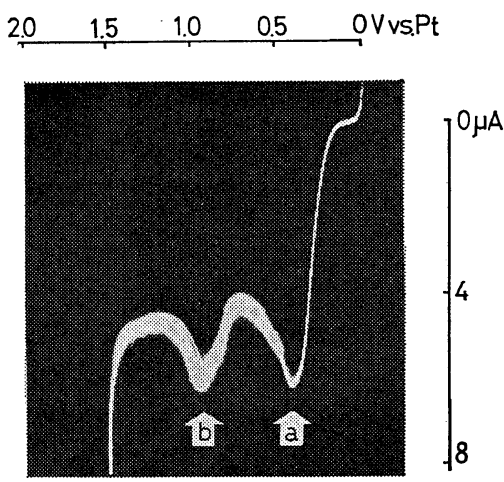

Figure 3. Oscillopolarogram of disodium diphenylethylene dimer (a) and disodium poly(4-vinylpyridine) (b): sweep rate, $0.3 \mathrm{~V} / \mathrm{sec}$; sweep range, 0 $2.0 \mathrm{~V}$ vs. Pt electrode.

oscillopolarograph, PE-20 of Yanagimoto Mfg. Co., Ltd. with a microplatinum electrode B, $5 \mathrm{~mm} \times 0.4 \mathrm{~mm} \phi$, and a cathodic electrode A, made of flat platinum cylinder, $20 \mathrm{~mm} \phi \times 10 \mathrm{~mm}$. Typical oscillopolarograms of mixtures of the naphthalene anion-anthracene dianion and diphenylethylene dimer dianion $\left({ }^{-} \mathbf{D}^{-}\right)$-living anion of poly(4-vinylpyridine) are shown in Figures 2 and 3 respectively.

Electrolysis of Disodium $\alpha$-Methylstyrere Tetramer

The electrolysis was performed in the cell as previously described ${ }^{9}$, which was divided into two compartments by sintered glass. Two smooth platinum electrodes, $1.0 \times 3.5 \mathrm{~cm}^{2}$, were sealed into the cell. After the cell, wherein $1.1 \mathrm{~g}$ of $\mathrm{NaAlEt}_{4}$ was placed as a supporting electrolyte, was thoroughly dried under vacuum, $60 \mathrm{~m} l$ of THF solution of disodium $\alpha$-methylstyrene tetramer was added into the cell through a breakable seal. During the electrolysis, the catholyte and anolyte were separately stirred by magnetic bars at room temperature. When the anolyte was completely decolorized, electrolysis was stopped and the catholyte and anolyte were separately treated with methanol. Subsequently, the volatile components were removed under reduced pressure and oligo- $\alpha$-methylstyrene produced was extracted from the residue. The gel-permeation chromatograms and the molecular weights of the oligomers were observed by GPC, Model 200 of Waters Associates Inc., and Vapor Pressure Molecular
Weight Apparatus, Model 115 of Hitachi Ltd., respectively.

\section{RESULTS AND DISCUSSION}

\section{Measurement of the Oxidation Potentials of the Carbanions}

The THF solution of fluorenyl anion gave an oxidation wave at $25^{\circ} \mathrm{C}$, whereas none of the neutral aromatic hydrocarbons gave an oxidation wave in this study. The oxidation wave of fluorenyl anion was attributed to a direct electron transfer from the carbanion to a platinum electrode based on the following results. Figure 4 showed a linear relationship between the anodic peak current of fluorenyl anion and the square root of the sweep rate as was expected in a typical oscillopolarographic measurement. The linear dependency of anodic peak current on the

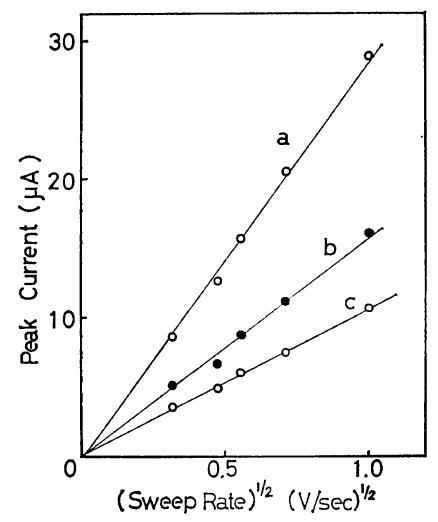

Figure 4. Peak current vs. (Sweep Rate) $)^{1 / 2}$ : concentration of fluorenyl anion, (a) $1.04 \times 10^{-3}$; (b) $5.29 \times 10^{-4}$; (c) $3.09 \times 10^{-4} \mathrm{~mol} / l$.

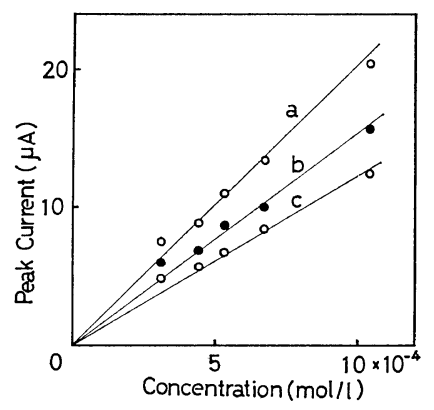

Figure 5. Peak current $v s$. concentration: sweep rate, (a) 0.5 ; (b) 0.3 ; (c) $0.2 \mathrm{~V} / \mathrm{sec}$. 


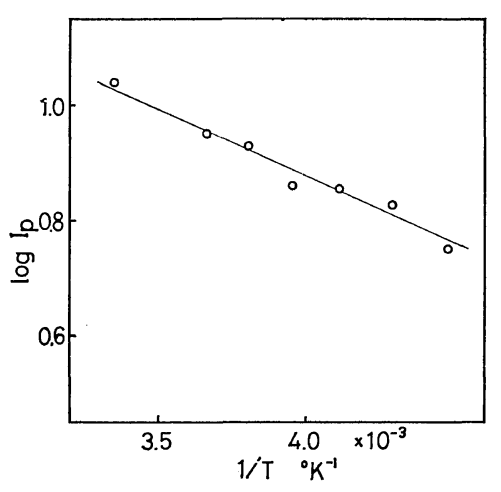

Figure 6. Dependence of the peak current on temperature.

concentration of fluorenyl anion, which was simultaneously measured at $356 \mathrm{~m} \mu$ by means of spectroscopy, was also observed as shown in Figure 5. Figure 6 showed the dependency of anodic peak current of the fluorenyl anion on temperature. From the slope of the straight line, the apparent activation energy of the anodic reaction was calculated as being about $1.1 \mathrm{kcal} / \mathrm{mol}$ which was regarded as a diffusion controlled reaction.

The oxidation waves for nine carbanions were observed as well as for the fluorenyl anion. The experimental results are summarized in Table I. Since it was difficult to measure the absolute oxidation potential vs. SCE or some other standard electrode in this study, the summit potentials of naphthalene anion and ${ }^{-} \mathrm{D}^{-}$were defined as the tentative standard potentials. By measuring the oxidation potentials of the carbanions and the standard anion simultaneously as shown in Figures 2 or 3, the differences between the summit potentials of the carbanions and the standard anion were observed. Because of the restriction of the sweep range, ${ }^{-} \mathrm{D}^{-}$was used as a standard anion when the oxidation potentials of polymer anions and fluorenyl anion were measured as shown in Table I. In Addition, in order to correct the summit potential for iR drop, the value of the peak potential was extrapolated to zero peak current as shown in Figures 7 and 8 . Plotting the peak potentials against the energy levels of HOMO's of the carbanions yielded a straight line whose slope was -1.1 as shown in Figure 9. This suggests that the anodic reaction is a direct transfer of the electron accomodated by HOMO of carbanion to the anode. If the electrode reaction is rever-

Table I. Oxidation potentials and energy levels of the highest occupied molecular orbitals of carbanions

\begin{tabular}{|c|c|c|c|}
\hline Carbanions & $E_{\mathrm{p}}^{\mathrm{a}}, \mathrm{V}$ & $E_{\mathrm{p}} \mathrm{b}, \mathrm{V}$ & $\begin{array}{l}\text { Energy level of } \\
\text { HOMO }^{10, c}, \mathrm{eV}\end{array}$ \\
\hline Naphthalene ${ }^{-}$ & $\begin{array}{c}(0) \\
\text { (standard) }\end{array}$ & & -5.53 \\
\hline Biphenyl- & 0 & & -5.56 \\
\hline Phenanthrene- & 0 & & -5.31 \\
\hline Stilbene $^{2-}$ & 0.27 & & -5.81 \\
\hline Anthracene ${ }^{2-}$ & 0.48 & & -6.03 \\
\hline Diphenylethylene dimer ${ }^{2-}$ & 1.13 & $\begin{array}{c}(0) \\
(\text { standard) }\end{array}$ & -7.06 \\
\hline$[\operatorname{Poly}(\alpha \text {-methylstyrene })]^{2-}$ & & 0 & -7.06 \\
\hline Polystyrene $^{2-}$ & 1.26 & 0 & -7.06 \\
\hline Poly(4-vinylpyridine) $)^{2-}$ & & 0.62 & $-7.40^{\mathrm{d}}$ \\
\hline Fluorene- & & 0.58 & -7.51 \\
\hline
\end{tabular}

a,b Expressed against the standard potential of naphthalene radical anion (a) or diphenylethylene dimer dianion (b).

c It is supposed that all $S$ overlap integral are zero. Coulomb integral $\alpha$ is $-7.06 \mathrm{eV}$ and resonance integral $\beta$ is $-2.49 \mathrm{eV}$.

d The adjustment made for the hetero molecule is as follows

$\alpha^{\prime}=\alpha+0.7 \beta$ for $-\mathrm{N}=$

$\beta^{\prime}=0.8 \beta \quad$ for $\quad-\mathrm{C}=\mathrm{N}-$ 


\section{Electrochemical Oxidation of Carbanions}

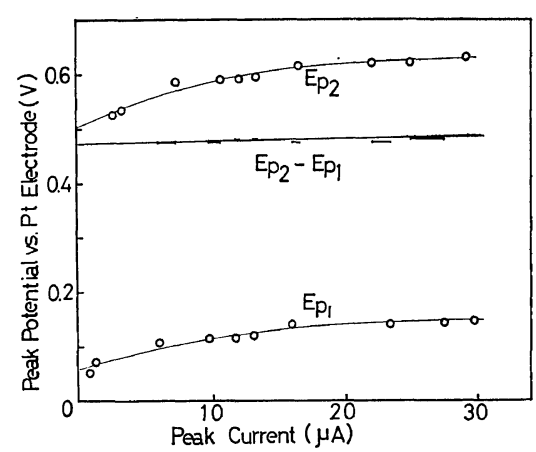

Figure 7. Peak potential vs. peak current: $E_{\mathrm{p} 1}$, sodium naphthalene; $E_{\mathrm{p} 2}$, disodium anthracene; $E_{\mathrm{p} 2}-E_{\mathrm{p} 1}$, difference of the peak potentials.

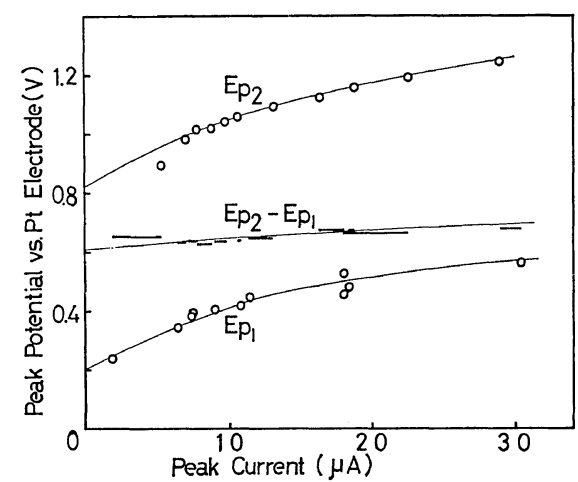

Figure 8. Peak potential vs. peak current; $E_{\mathrm{p} 1}$, disodium diphenylethylene dimer; $E_{\mathrm{p} 2}$, disodium poly(4-vinylpyridine).

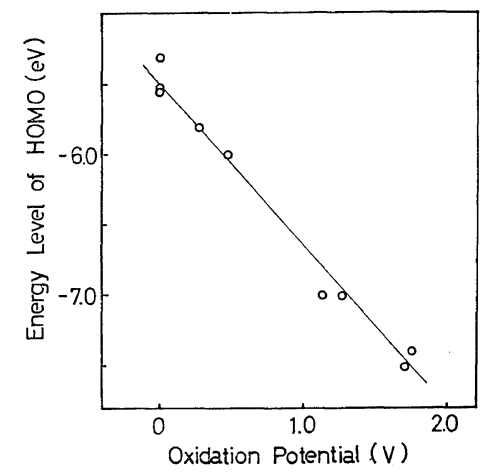

Figure 9. Energy level of HOMO vs. oxidation potential.

sible, the oxidation potential of the radical anion such as naphthalene $e^{-}$, phenanthrene ${ }^{-}$, biphenyl ${ }^{-}$, is equal to the reduction potential of the neutral hydrocarbon. The reduction potentials of bi- phenyl, naphthalene and phenanthrene are somewhat different from (about $0.1 \mathrm{~V}$ ) each other ${ }^{13}$, whereas the difference between the oxidation potentials of these carbanions can not be observed. Although this might be explained by irreversibility of the electrode reaction, the detailed mechanism of the reaction can not be discussed at this satge. The oxidation potentials correspond to the reactivities of the arene anions, which were regarded as anionic initiators: the carbanions which exhibit less noble peak potentials, e.g., naphthalene anion and anthracene dianion, rapidly initiate the polymerization of styrene. On the other hand, the fluorenyl anion, which has a more noble oxidation potential, could not react with styrene monomer. Concerning propagating ends, a similar correlation was observed, although the electron-transfer reaction and propagation reaction were not considered as having the same transition state. The rate constant of addition of styrene to polystyryl anion was $950 \mathrm{l} / \mathrm{mol} \mathrm{sec}{ }^{2}$, whereas that of styrene and poly(4-vinylpyridine) anion was $c a$. $1 \mathrm{l} / \mathrm{mol} \mathrm{sec}^{3}$. The latter anion showed $c a$. 0.6-V more noble oxidation potential than that of the former anion as shown in Table $I$. Although the peak potential of ${ }^{-} \mathrm{D}^{-}$was nearly equal to that of polystyryl anion, the rate constant of addition of styrene to ${ }^{-} \mathrm{D}^{-}$is about 1000 times lower than that of the homopolymerization of styrene. Steric hindrance would be encountered in the former case as was mentioned by Szwarc, et $a l^{4}$. The rate of polymerization was also affected by the structure of the ionic species, e.g., ion pairs and/or free ions. An attempt to distinguish the solvent separated ion pair from the contact ion pair of fluorenyl anion in the various solvents and electrolytes at various temperatures by means of ocillopolarographic technique failed.

Electrolysis of Disodium $\alpha$-Methylstyrene Tetramer

The direct electron transfer from the carbanion to anode is also demonstrated by the electrolysis of disodium $\alpha$-methylstyrene tetramer (DMT). When $4.0 \mathrm{~g}$ of DMT in THF was electrolyzed, 1.8 and $1.5 \mathrm{~g}$ of the $\alpha$-methylstyrene oligomers, whose molecular weights were 485 and 1000 , were obtained from the catholyte and anolyte, respectively. The gel-permeation chromatograms of these oligomers are shown in Figure 10. These 


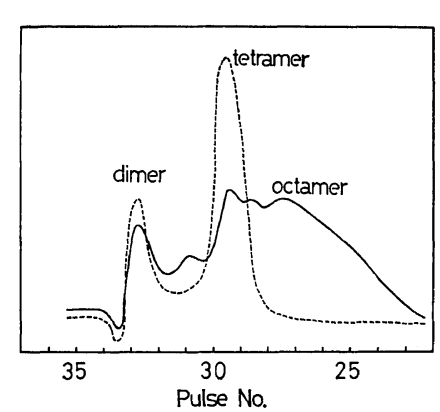

Figure 10. Gel-permeation chromatograms of $\alpha$ methystyrene oligomers obtained from the anolyte (solid line) and the catholyte (dashed line): solvent, THF, flow rate, $1.0 \mathrm{~m} / / \mathrm{min}$.

curves showed that the the distribution of the molecular weight of the cathodic oligomer was unchanged compared with the original DMT fed in the cell prior to the electrolysis, whereas the molecular weight of the anodic oligomer was more than twice of the initial value. The increase of the molecular weight suggests that the living oligo- $\alpha$-methylstyrene might have coupled with each other in the anodic compartment. Two mechanisms including a one and a two electron-transfer process are postulated for the coupling reaction: in the case of a one electron transfer, living oligo- $\alpha$-methylstyrene would be oxidized to form a radical species followed by the radical coupling as shown in eq 1 . Iwakura, et $a l^{14}$., described a reaction of DMT with a ketone which produced poly ( $\alpha$-methylstyrene) whose molecular weight was $(2-3) \times 10^{3}$, suggesting an electron transfer from the carbanion to the ketone and a radical coupling of the $\alpha$ methylstyrene teramer.<smiles>CCC(C)(c1ccccc1)C(C)(CCC(C)(c1ccccc1)c1ccccc1)C(C)(C)CCC(C)(c1ccccc1)c1ccccc1</smiles>

A two electron transfer would result in the formation of the carbocation which would react with living oligmer or $\mathrm{AlEt}_{4}{ }^{-}$as follows<smiles>C#CC(C)(CC[C+](C)c1ccccc1)c1ccccc1</smiles>

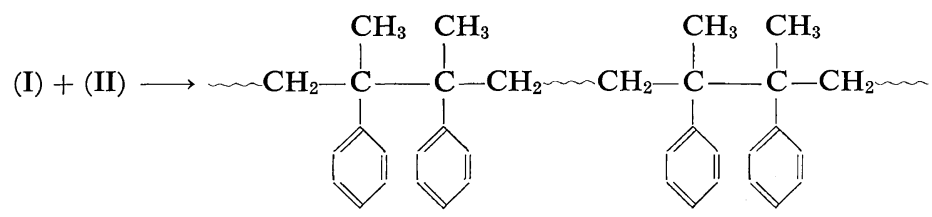

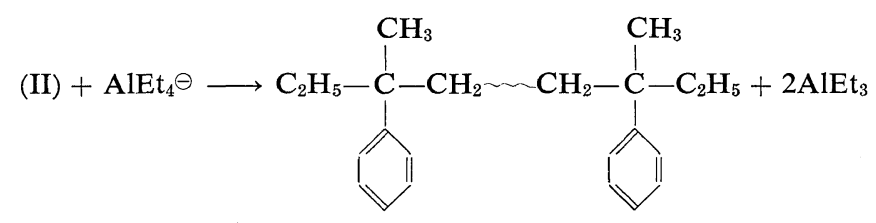


As shown in eq 4, the cation produced would be attacked predominantly by $\mathrm{AlEt}_{4}{ }^{-}$whose concentration is much higher than that of living anions. Consequently such an ionic coupling reaction (eq 3) would encounter difficulties in successive couplings. Octamer and higher oligomers were actually obtained from the anolyte as shown in Figure 10. DMT, $3.2 \times 10^{-3} \mathrm{~mol}$, were placed initially in the anodic compartment and the amount of current passed was $4.4 \times 10^{-3}$ Faraday. On the assumption that a transfer of two electrons causes one coupling reaction as shown in eq $1-3$, the molecular weight of anodic oligomer is calculated to be 1590 , whereas the observed value is 1000 . These results suggest that the one electron-transfer reaction is favored as compared with a two electron transfer.

\section{REFERENCES}

1. N. Yamazaki, I. Tanaka, and Nakahama, $J$. Macromol. Sci.-Chem., A2, 1121 (1968).

2. C. Geacintov, J. Smid, and M. Szwarc, $J$. Amer. Chem. Soc., 84, 2508 (1962).
3. C. H. Lee, J. Smid, and M. Szwarc, Trans. Faraday Soc., 59, 1192 (1963).

4. E. Ureta, J. Smid, and M. Szwarc, J. Polym. Sci., Part A-1, 42219 (1966).

5. B. L. Funt, S. N. Bhadani, and D. Richardson, ibid., 4, 2871 (1966).

6. N. Yamazaki, S. Nakahama, and S. Kambara, ibid., Part B, 3, 57 (1965).

7. B. L. Funt and S. N. Bhadani, ibid., Part C, 23, (1) 1 (1968).

8. K. Ziegler, "Organometallic Chemistry," H. Zeiss, Ed., Reinhold Publishing Corp. New York, N. Y., 1960, p 251.

9. S. Nakahama, S. Hino, and N. Yamazaki, Polymer J., 2, 56 (1971).

10. C. A. Coulson and A. Streitwieser, Jr., "Dictionary of $\pi$-Electron Calculations", Pergamon Press Ltd., Oxford, 1965.

11. C. J. Ballhausen and H. B. Gray, "Molecular Orbital Theory" Benjamin Inc., New York, N.Y., 1964, p 158.

12. C. Sandrofy, Bull. soc. chim. France., 1949, p 615.

13. J. Jagur-Grodzinski, M. Feld, S. L. Yang, and M. Szwarc, J. Phys. Chem., 69, 628 (1965).

14. Y. Iwakura, F. Toda, H. Katsuki, and H. Watanabe, J. Polym. Sci., Part B, 5, 1013 (1967). 